OPEN ACCESS

Edited by:

Daniele Vergara,

University of Salento, Italy

Reviewed by:

Marina Damato,

University of Salento, Italy

Kristina Andrijauskaite,

The University of Texas Health Science Center at San Antonio, United States

${ }^{*}$ Correspondence:

Fang Wu

wufang4461@csu.edu.cn

Specialty section:

This article was submitted to

Molecular and Cellular Oncology,

a section of the journal

Frontiers in Cell and Developmental

Biology

Received: 14 September 2021

Accepted: 02 November 2021

Published: 19 November 2021

Citation:

Tian W, Liu Y, Cao C, Zeng Y, Pan Y, Liu X, Peng Y and Wu F (2021) Chronic

Stress: Impacts on Tumor Microenvironment and Implications for

Anti-Cancer Treatments.

Front. Cell Dev. Biol. 9:777018.

doi: 10.3389/fcell.2021.777018

\section{Chronic Stress: Impacts on Tumor Microenvironment and Implications for Anti-Cancer Treatments}

\author{
Wentao Tian ${ }^{1,2}$, Yi Liu ${ }^{3}$, Chenghui Cao ${ }^{1,2}$, Yue Zeng ${ }^{1}$, Yue Pan ${ }^{1}$, Xiaohan Liu ${ }^{1}$, Yurong Peng ${ }^{1}$ \\ and Fang $\mathrm{Wu}^{1,4,5,6 *}$

\begin{abstract}
${ }^{1}$ Department of Oncology, The Second Xiangya Hospital, Central South University, Changsha, China, ${ }^{2}$ Xiangya School of

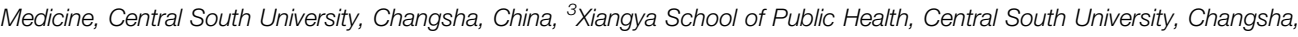
China, ${ }^{4}$ Hunan Cancer Mega-Data Intelligent Application and Engineering Research Centre, Changsha, China, ${ }^{5}$ Hunan Key Laboratory of Tumor Models and Individualized Medicine, The Second Xiangya Hospital, Central South University, Changsha, China, ${ }^{6}$ Hunan Key Laboratory of Early Diagnosis and Precision Therapy in Lung Cancer, The Second Xiangya Hospital, Central South University, Changsha, China
\end{abstract}

Chronic stress is common among cancer patients due to the psychological, operative, or pharmaceutical stressors at the time of diagnosis or during the treatment of cancers. The continuous activations of the hypothalamic-pituitary-adrenal (HPA) axis and the sympathetic nervous system (SNS), as results of chronic stress, have been demonstrated to take part in several cancer-promoting processes, such as tumorigenesis, progression, metastasis, and multi-drug resistance, by altering the tumor microenvironment (TME). Stressed TME is generally characterized by the increased proportion of cancer-promoting cells and cytokines, the reduction and malfunction of immune-supportive cells and cytokines, augmented angiogenesis, enhanced epithelial-mesenchymal transition, and damaged extracellular matrix. For the negative effects that these alterations can cause in terms of the efficacies of anti-cancer treatments and prognosis of patients, supplementary pharmacological or psychotherapeutic strategies targeting HPA, SNS, or psychological stress may be effective in improving the prognosis of cancer patients. Here, we review the characteristics and mechanisms of TME alterations under chronic stress, their influences on anti-cancer therapies, and accessory interventions and therapies for stressed cancer patients.

Keywords: chronic stress, tumor microenvironment, glucocorticoid, catecholamine, anticancer treatment

\section{INTRODUCTION}

Chronic stress, which is associated with the constant activation of the hypothalamic-pituitaryadrenal (HPA) axis and the sympathetic nervous system (SNS) and release of stress hormones including catecholamines and glucocorticoids, occurs frequently in cancer patients during cancer diagnosis and treatment (Gil et al., 2012). The catecholamines and glucocorticoids then activate the adrenergic receptors and glucocorticoid receptors, which belong to the $G$ protein-coupled receptor (GPCR) family and nuclear receptor family respectively, to activate several signaling pathways or alter the transcriptions directly. Unlike the transient secretion of stress hormones in acute stress, lasting elevations of catecholamines and glucocorticoids not only cause mental diseases such as anxiety disorder and depression, but also takes part in the 
tumorigenesis, progression, metastasis, and drug resistance of various cancers (Reiche et al., 2004). A meta-analysis suggested that stress-related psychosocial factors are associated with higher cancer incidence in initially healthy populations, poorer survival in patients with diagnosed cancer, and higher cancer-related mortality (Chida et al., 2008). Thus, chronic stress is a noteworthy issue in terms of anti-cancer treatments.

Tumor microenvironment (TME), consisting of tumor cells, tumor stromal cells, and non-cellular components, is largely involved in the formation, maintenance, and multidrug resistance (MDR) of cancers (Baghban et al., 2020). Initially, the pro-cancer effects of persistent activations of the HPA axis and SNS under chronic stress are thought to depend mostly on their regulations on systematic immune functions (Sloan et al., 2007; Silverman and Sternberg, 2012). Nowadays, extensive studies have revealed that chronic stress is also responsible for altering the TME, including the tumor cells, cancer stromal cells, and extracellular matrix (ECM), thus participants in cancerpromoting processes.

This review focuses on the consequences of chronic stress on TME and summarizes the characteristics and mechanisms of TME alterations under chronic stress, based on which we emphasize the negative effects of chronic stress on anti-tumor therapies and the implications for formulating well-rounded anticancer strategies.

\section{FEATURES OF TME UNDER CHRONIC STRESS}

The TME of patients with chronic stress is distinct from the TME of patients without it, manifested in the differences in the types, statuses, and quantities of immune cells, the class and amounts of cytokines, augmented angiogenesis, enhanced epithelialmesenchymal transition (EMT), and damaged ECM.

\section{Immune Cells}

Generally, the effects of chronic stress on Immune cells in TME are embodied in decreased numbers or functions of immunesupportive cells and increased amounts of exhausted immune cells and immunosuppressive cells (Figure 1).

Dendritic cells (DCs) are essential in tumor antigen presentation and the initiation of cancer adaptive immunity (Gardner and Ruffell, 2016). Nonetheless, Chronic stress or exposure to glucocorticoids disabled immature DCs to undergo full maturation and prime Th1 cells and $\mathrm{CD}^{+} \mathrm{T}$ cells efficiently in a rodent model with melanoma, yet the functions of mature DCs were unaffected (Matyszak et al., 2000; Sommershof et al., 2017).

$\mathrm{T}$ lymphocytes serve as the main force in cancer adaptive immunity, yet chronic stress leads to a reduction and dysfunction of immune-supportive $\mathrm{T}$ cells along with a raise of immunosuppressive $\mathrm{T}$ cells (Thommen and Schumacher, 2018). A reduction of cytotoxic $T$ lymphocytes (CTLs) in TME occurred after impaired DC maturation in both healthy mice and the mice with melanoma (Bucsek et al., 2017;
Sommershof et al., 2017). Endogenous glucocorticoids inhibited responses of DCs and T cells to type I interferons (IFNs) and IFN- $\gamma$, respectively, which compromised the differentiation or activations of these cells in the TME of mice (Yang et al., 2019). Endogenous glucocorticoid signaling led to dysfunctional CD8+ $\mathrm{T}$ cells characterized by increased expressions of PD-1, TIM-3, and Lag3 (Acharya et al., 2020). Stress-induced $\beta$-AR activation suppressed T-cell receptor (TCR) signaling in a rodent melanoma model and a rodent colon cancer model (Qiao et al., 2021). $\beta 2-\mathrm{AR}$ activations in regulatory $\mathrm{T}$ (Treg) cells increased their immunosuppressive functions associated with decreased interleukin (IL-2) level and improved differentiation of CD4+ Foxp3- T cells into Foxp3+ Tregs in a rodent model (Guereschi et al., 2013). Stressed mice also had increased suppressive CD25+ cells in tumors of UVinduced squamous cell carcinoma (Saul et al., 2005).

Natural killer (NK) cells, acting through NK cell cytotoxicity (NKCC), represent pivotal cells in tumor innate immunity (DeNardo and Ruffell, 2019). Surgical stress reduced NKCC and NK cell expression of Fas ligand and CD11a in the blood of mice with melanoma or Lewis lung carcinoma (Glasner et al., 2010). Similar diminished NKCC was observed in blood samples from stressed rodent models with leukemia and breast cancer (BenEliyahu et al., 1999). A study on 42 patients with epithelial ovarian cancer revealed that psychological distress was related to lower NK cytotoxicity in TIL (Lutgendorf et al., 2005). Another study revealed impaired NK cell lysis, associated with altered expression of killer immunoglobin-like receptors, in breast cancer patients with high levels of psychological stress (Varker et al., 2007).

Myeloid-derived suppressor cells (MDSCs), presenting in individuals with cancer or chronic stress, play a key role in immune suppression (Gabrilovich, 2017). The operative stress increased the number of immunosuppressive MDSCs in TME (Ma et al., 2019). Similarly, an increase of MDSCs and Treg cells was detected in another stressed male rodent model (Schmidt et al., 2016).

Macrophages are also important components of TME, with which tumors enhance cell proliferation, angiogenesis, and metastasis (DeNardo and Ruffell, 2019). Prostate cancer patients with a higher score of depression revealed higher $\mathrm{CD}^{+} 8^{+}$tumor-associated macrophage (TAM) infiltration (Cheng et al., 2019), and daily restraint stress increased infiltration of CD68+ macrophages in rodent models of ovarian cancer as well (Colon-Echevarria et al., 2020). Moreover, $\beta 2-\mathrm{AR}$ activation promoted macrophages to polarize to immunosuppressive M2 subtype in a rodent breast cancer model (Qin et al., 2015).

In addition, cancer-associated fibroblast (CAF) can regulate TME through cell-cell contact, releasing growth factors, and remodeling the extracellular matrix (Chen and Song, 2019). The activation of a2-ARs boosts the growth and proliferation of fibroblasts, increasing the concentration of growth factors in TME (Bruzzone et al., 2011; Shan et al., 2014).

\section{Cytokines}

Unsurprisingly, the cytokines originating from both tumor cells and stromal cells in stressed TME show cancer- 
promoting properties (Figure 1). Glucocorticoids reduced the number of IFN- $\gamma$-producing cells and the amount of IFN- $\gamma$ produced in TME of the rodent melanoma model (Matyszak et al., 2000; Sommershof et al., 2017). Increased MDSCs in TME up-regulated transforming growth factor-beta 1 (TGF$\beta 1$ ), vascular endothelial growth factor (VEGF), and Interleukin-10 (IL-10) in rodent breast cancer models (Ma et al., 2019). And glucocorticoid could upregulate the expression of TGF- $\beta$ receptor type II on ovarian cancer cells and enhance their responsiveness to TGF- $\beta 1$ (Chen et al., 2010). The activation of $\beta$-AR enhanced the secretion of neuropeptide Y (NPY) in a rodent prostate cancer model and subsequently promoted TAM trafficking (Cheng et al., 2019). The level of IL- 6 was elevated in the TME of a prostate cancer model due to TAM activation and tumor cell secretion induced by $\beta$-AR signaling (Powell et al., 2013; Cheng et al., 2019). Elevations of matrix metalloproteinase (MMP)-9 in TAMs were detected in epithelial ovarian cancer tissue of patients with chronic stress (Lutgendorf et al., 2008). The expressions of VEGF, MMP-2, and MMP-9 were increased in a stressed rodent model of ovarian carcinoma and another stressed rodent model of lung carcinoma (Thaker et al., 2006; Wu et al., 2015), and the same upregulations were detected in nasopharyngeal carcinoma tumor cells treated with norepinephrine (Yang E. V. et al., 2006). Similar upregulations of VEGF and MMP-2 were observed in a rodent oral cancer model (Xie et al., 2015). The upregulated expression of VEGF, IL-8, and IL-6 was also observed in human melanoma tumor cell lines treated with norepinephrine (Yang et al., 2009). Elevated PGE2 secretion was detected in epinephrine-treated ex vivo human breast and colon cancer explant and mammary tumors of chronic stressexposed mice due to activation (Muthuswamy et al., 2017). Additionally, the cytokine analyses in a stressed rodent ovarian cancer model revealed up-regulation of a large scale of cytokines, including platelet-derived growth factor AA (PDGF-AA), epithelial cell-derived neutrophil-activating peptide (ENA-78), angiogenin, VEGF, granulocytemacrophage colony-stimulating factor (GM-CSF), IL-5, Lipocalin-2, macrophage migration inhibitory factor (MIF), and transferrin receptor (TfR) (Colon-Echevarria et al., 2020).

\section{Angiogenesis}

Overexpression of VEGF and other pro-angiogenic factors like IL-6, TGF-beta, and MMPs, as one of the critical features of stressed TME, leads to enhanced angiogenesis of solid tumors (Kerbel, 2008). This effect was observed in the stressed rodent models of ovarian cancer, oral cancer, and lung cancer, as mentioned above (Thaker et al., 2006; Wu et al., 2015; Xie et al., 2015). Additionally, the expression of VEGFR-2 on endothelial cells was upregulated in the stressed rodent lung cancer model, which also contributes to enhanced angiogenesis (Wu et al., 2015). Moreover, Chronic stress promoted VEGF/FGF2-mediated angiogenesis in a rodent model of breast cancer by down-regulating peroxisome proliferator-activated receptor $\gamma(\operatorname{PPAR} \gamma)$ (Zhou et al., 2020). Enhanced angiogenesis induced by chronic stress and $\beta$-adrenergic signaling via histone deacetylase-2 (HDAC2)-mediated suppression of thrombospondin-1 was also observed in a stressed model of prostate cancer (Hulsurkar et al., 2017). What's worse, chaotic and unfunctional vessels induced by intense angiogenesis lead to other problems like acidosis and hypoxia in TME (Neri and Supuran, 2011; Rey et al., 2017).

\section{Epithelial-Mesenchymal Transition}

As TGF- $\beta$ family signaling is crucial in EMT, chronic stress also promotes EMT because TGF- $\beta 1$ is markedly upregulated in stressed TME (Lamouille et al., 2014). A high concentration of TGF- $\beta 1$ induces EMT of tumor cells and promotes tumor metastasis in stressed rodent models with breast cancer (Ma et al., 2019). Norepinephrine induced EMT, reflected in E-cadherin downregulation and vimentin upregulation, via $\beta$-AR/TGF- $\beta 1 / \mathrm{p}$-Smad3/Snail pathway or $\beta$-AR/TGF- $\beta 1 / \mathrm{HIF}$ $1 \alpha /$ Snail pathway in gastric, colonic, and pneumonic cancer cell lines in vitro (Shan et al., 2014; Zhang et al., 2016). In addition, Chronic stress downregulates E-cadherin expression and upregulates vimentin expression through the activation of miR-337-3p/STAT3 in a stressed rodent model with breast cancer (Du et al., 2020).

Moreover, given that the activation of ARs can induce the activations of protein kinase A (PKA) and protein kinase $\mathrm{C}$ (PKC) (Biazi et al., 2018; Durkee et al., 2019; Cole and Sood, 2012) (Figure 2), chronic stress can be associated with EMT via $\mathrm{PKA}$ and $\mathrm{PKC}$ signaling. It is well established that $\mathrm{PKC}$ promotes EMT by activating various downstream molecules. PKCa was regarded as a central signaling node for EMT in breast cancer (Tam et al., 2013). PKC $\theta$ was reported to induce EMT through TGF- $\beta$ and NF- $\kappa$ B signaling (Zafar et al., 2014; Zafar et al., 2015), and PKC $\delta$ could induce EMT via phosphorylation of Bcl-2 associated athanogene 3 (BAG3) (Li et al., 2013). Moreover, a study showed that PKCinduced EMT was associated with a down-regulation of carbonic anhydrase 12 (CAXII) (Vergara et al., 2020). In contrast, the activation of PKA favored the epithelial type and contributed to the mesenchymal-epithelial transition (MET) of the tumor cells (Nadella et al., 2008; Pattabiraman et al., 2016). Yet, research showed that PKA promoted TGF-ßinduced EMT (Yang Y. et al., 2006), and enhanced activity of PKA plays an important role in hypoxia-mediated EMT (Shaikh et al., 2012). However, research on $\mathrm{PKA} / \mathrm{PKC}$-induced EMT using stress or stress hormone-treated models is lacking, so the exact roles of PKA and PKC in chronic stress-induced EMT still need further investigations.

Additionally, it is notable that chronic stress is also associated with deteriorations of gut microbiota (Gao et al., 2018), which can facilitate EMT through microbiota-host interactions (Vergara et al., 2019).

\section{Extracellular Matrix}

Elevations of MMPs were present in TME of various cancers (Thaker et al., 2006; Lutgendorf et al., 2008; Wu et al., 2015; Xie et al., 2015), which are likely to cause damages to ECM and 


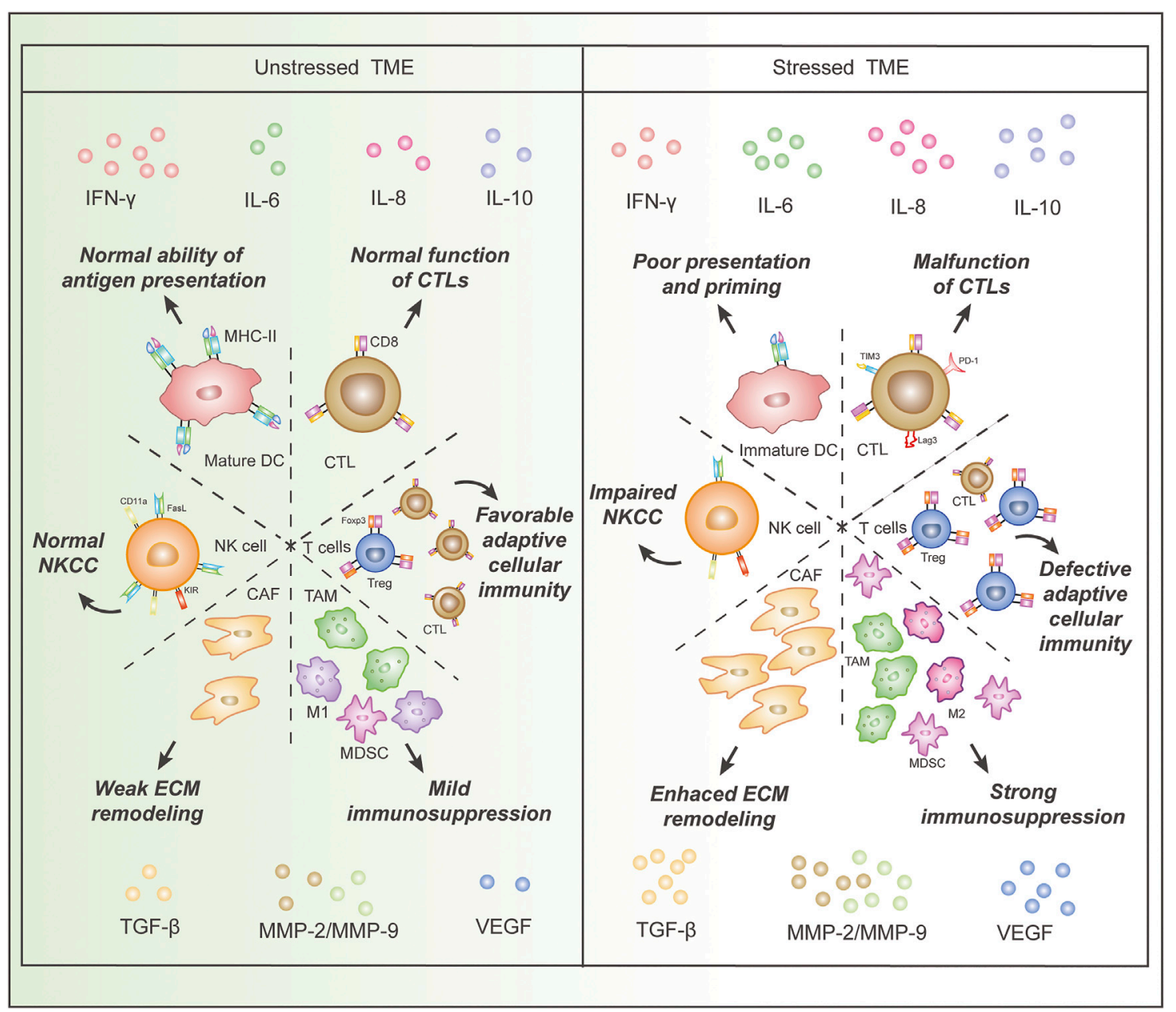

FIGURE 1 | Comparison of immune cells and cytokines in the stressed and unstressed tumor microenvironment (TME). Stressed TME is characterized by (I), decreased proportion and dysfunction of immune-supportive cells, including DCs and CTLs, as well as an increased proportion of cancer-promoting cells, such as MDSCs, Treg cells, CAFs, TAMs, and M2 macrophages; (II), increased concentrations of cytokines that impair anti-cancer immunity and induce angiogenesis, epithelialmesenchymal transition, and extracellular matrix damage, as well as a decreased concentration of IFN- $\gamma$. Abbreviations: IFN, interferon; MMP, matrix metalloproteinase; IL, interleukin; TGF, transforming growth factor; VEGF, vascular endothelial growth factor; DC, dendritic cell; CTL, cytotoxic T lymphocyte, CAF, cancer-associated fibroblast; Treg, regulatory T cell; MDSC, myeloid-derived suppressor cell; TAM, tumor-associated macrophage;NK cell, natural killer cell; FasL, Fas ligand; NKCC, NK cell cytotoxicity; ECM, extracellular matrix.

promote cancer metastasis (Najafi et al., 2019). Additionally, glucocorticoids can downregulate the synthesis of tenascin-C, a vital protein in the extracellular matrix, in a rodent Wilms' tumor model, even though local stimulatory growth factors are present (Talts et al., 1995).

\section{Metabolism}

Chronic stress can cause molecular and functional recalibrations of mitochondria and metabolic disorders in immune cells (Picard and McEwen, 2018; Fan et al., 2019), which can alter the metabolic features in TME. Also, hostile TME with limited oxygen and nutrients can lead to metabolic reprogramming of local $\mathrm{T}$ cells and impair their functions (Pearce et al., 2013). Chronic stressinduced up-regulation of epinephrine could activate lactate dehydrogenase A (LDHA) to generate lactate and promote breast cancer stem-like properties in a rodent model (Cui et al.,
2019). Besides, $\beta$-AR activation depressed endothelial oxidative phosphorylation and turned on the angiogenic switch for tumor progression in a rodent prostate cancer model (Zahalka et al., 2017). Additionally, the activations of PKC and PKA can lead to unfavorable metabolic alterations and fuel cancer progression (Aggarwal et al., 2019; Liu et al., 2019; Vergara et al., 2020).

\section{MECHANISMS FOR TME ALTERATIONS UNDER CHRONIC STRESS}

The TME alterations under chronic stress are mainly derived from activated AR signaling and glucocorticoid signaling. Under chronic stress, SNS is constantly activated, resulting in a high concentration of catecholamine in solid tumor tissues, which drives from both circulating blood and local sympathetic neurons 


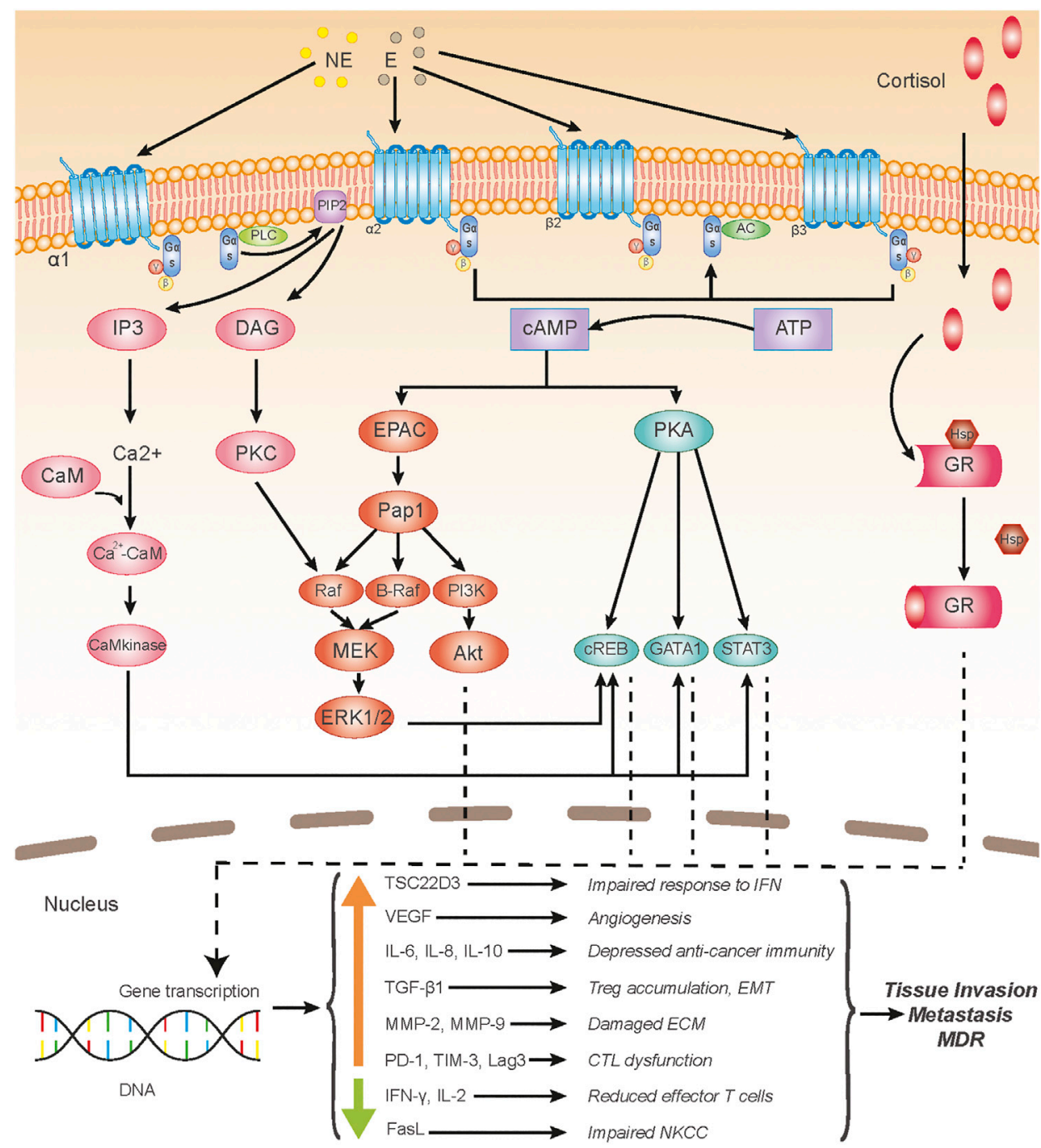

FIGURE 2 | Chronic stress-induced signaling pathways acting upon tumor microenvironment. Adrenergic receptors (ARs), including $\alpha-A R$, $\beta 2-A R$, and $\beta 3$-AR get involved in chronic stress-induced tumor microenvironment (TME) alterations; ARs are G protein-coupled receptors (GPCRs), the binding of AR agonists, such as norepinephrine and epinephrine, to which activates intracellular Gas protein. Activated Gas either activates PLC ( $\alpha 1-\mathrm{AR})$ or AC ( $\alpha 1-\mathrm{AR}, \beta 2-\mathrm{AR}$, and $\beta 3-\mathrm{AR})$, which subsequently induces an intracellular increase of IP3 and DAG, or CAMP, respectively, and then the second messengers initiate activation of several signaling pathways, including the PKA, PKC, EPAC, and Ca ${ }^{2+}$ CaM pathways. Glucocorticoid receptors (GRs), consisting of the glucocorticoid-binding subunit and Hsp 90 protein, belong to the nuclear receptor family and locate intracellularly; after glucocorticoids permeate through the cell membrane and bind to GRs, the Hsp protein depolymerizes from the polymeric substance and the main subunits of GRs translocate into the nucleus and initiate gene transcriptions. Transcriptions of various genes of cytokines or ligands are up-regulated or down-regulated, altogether causing the deterioration of the TME, which leads to a large scale of cancer-promoting effects. Abbreviation: NE, norepinephrine; E, epinephrine; PLC, phospholipase C; PIP2, phosphatidylinositol (4,5) bisphosphate; AC, adenylatecyclase; IP3, inositol triphosphate; DAG, diacylglycerol; CaM, calmodulin; PKC, protein kinase C; ATP, adenosine triphosphate; CAMP, cyclic adenosine monophosphate; PKA, protein kinase A; EPAC, exchange protein activated by adenylyl cyclase; Pap1, production of anthocyanin pigment 1; PI3K, phosphatidylinositol 3-kinase; MEK, mitogen-activated protein kinase kinase (MAPKK); ERK, extracellular regulated protein kinase; CREB, cAMP-responsive element-binding protein; GATA1, GATA Binding Protein 1; STAT3, signal transducer and activator of transcription 3; GR, glucocorticoid receptor; Hsp, heat shock protein; IFN, interferon; NKCC, NK cell cytotoxicity; ECM, extracellular matrix; CTL, cytotoxic T lymphocyte; EMT, epithelial-mesenchymal transition; MDR, multidrug resistance.

(Reiche et al., 2004). Additionally, endogenous glucocorticoids, deriving from the adrenal cortex, of which the concentration in the blood increases under chronic stress via the HPA axis, easily diffuse across the membrane of various cells in TME (Kadmiel and Cidlowski, 2013). One thing to point out here is that the enhanced $\beta$-adrenergic signaling and glucocorticoid signaling in TME can be induced by not only chronic stress, but also TME hypoxia (Chiarugi and Filippi, 2015).
a-AR signaling is partly responsible for TME alterations. There are two subtypes of $\alpha$-ARs, including $\alpha 1-\mathrm{AR}$ and $\alpha 2-\mathrm{AR}$, both of which belong to the GPCR family (Taylor and Cassagnol, 2021). The activation of a1-AR leads to the increase of intracellular calcium concentration via the PLC-IP3/DAG pathway, while the activation of a2-AR results in the inhibition of adenylyl cyclase, which decreases the concentration of cytoplasmic calcium and cAMP (Biazi et al., 2018; Durkee et al., 2019) (Figure 2). 
$\beta$-ARs are expressed on the membranes of various tumor cells and tumor-related cells, such as immune cells, fibroblast, and epithelial cells, and epithelial cells, and two of the three subtypes of $\beta$-ARs, including $\beta 2-\mathrm{AR}$ and $\beta 3$-AR, take part in tumorous $\beta$-signaling (Daly and McGrath, 2011; Calvani et al., 2020). The binding of catecholamine, like epinephrine and norepinephrine, to $\beta$-ARs, contributes to the activation of guanylate cyclase, leading to transient cyclic adenosine monophosphate (cAMP) flux, which subsequently activates protein kinase A (PKA) and guanine nucleotide exchange protein activated by adenylyl cyclase (EPAC) (Cole and Sood, 2012). The two latter proteins activate a variety of intracellular pathways which switch on or off the transcriptions of genes, associating with inflammation, angiogenesis, tissue invasion, distant metastasis (Thaker et al., 2006; Cole and Sood, 2012; Duan et al., 2019) (Figure 2).

Glucocorticoids can be produced by the adrenal cortex and translocated to the tumor, or produced locally by TAMs (Acharya et al., 2020). Glucocorticoid receptors (GRs), located intracellularly, once activated by glucocorticoid, get involved in the formation of a complex and translocate to nuclei, which induce transcriptionally activation or suppression of gene expressions via direct interactions with DNA (Timmermans et al., 2019). For instance, TSC22D3 is upregulated in response to stress by glucocorticoid signaling, which blocks the response of DC to type I IFN and IFN- $\gamma^{+}$T cell activation (Yang et al., 2019) (Figure 2).

\section{CHRONIC STRESS INFLUENTS ANTI-CANCER THERAPY}

It has been widely accepted that the TME profile plays a dominant role in determining the efficacies of anti-cancer therapies (RomaRodrigues et al., 2019). Not surprisingly, the TME alterations under chronic stress have negative impacts on the efficacies of cancer treatments, including chemotherapy, immunotherapy, and targeted therapy.

\section{Chemotherapy}

Chronic stress-induced endogenous glucocorticoids have unfavorable effects on the therapeutic response to chemotherapy. Dexamethasone increased the adhesion to ECM and the resistance to cisplatin and paclitaxel in two human ovarian cancer cells (Chen et al., 2010). The therapeutic of oxaliplatin (OXA)-based chemotherapy effect was largely compromised in social-defeat (SD)-conditioned mice (Yang et al., 2019). And a high expression of the glucocorticoid receptors (GR) was correlated with shorter metastasis-free survival in triple-negative breast cancer (TNBC) patients undergoing chemotherapy (Chen et al., 2015).

Endogenous catecholamines, such as norepinephrine and epinephrine, also interfere with chemotherapy. Catecholamines reduced p53 protein concentrations in cancer cells and increased the genetic instability of these cells, which significantly inhibited paclitaxel-induced and cisplatin-induced apoptosis in ovarian cancer cells (Hara et al., 2011; Kang et al., 2016). Yet, reduction of stress-related signaling potentiated the effect of chemotherapy in cancer patients has also been demonstrated (Mravec et al., 2020).

\section{Immunotherapy}

Chronic-stress induced reductions of CD8+ $\mathrm{T}$ cells and CTLs result in a cancer vaccine failure in a rodent melanoma model (Sommershof et al., 2017). Dysfunction of CD8 ${ }^{+}$TILs induced by endogenous glucocorticoid signaling is associated with failure to respond to checkpoint blockade in both preclinical models and melanoma patients (Acharya et al., 2020). Increased infiltration of regulatory T-cells, decreased amount of CD8+ lymphocytes in tumor sites were observed in bladder-tumor-bearing mice treated with anti-PD-L1 under chronic stress. Therefore, chronic psychological stress could weaken the potency of anti-PD-L1 immunotherapy (Zhou et al., 2021).

A glucocorticoid-inducible molecule, TSC22D3 plays an important role in stress-induced immunosuppression as well as perturb responses to prophylactic tumor vaccination and PD-1-targeted immunotherapy (Yang et al., 2019). In addition, psychological stress down-regulated the expression of interleukin-2 (IL-2) receptor in peripheral blood leukocytes, affects the therapeutic efficacy of IL-2 immunotherapy in renal cell cancer patients (Zhang et al., 2020).

\section{Molecule-Targeted Therapy}

Since chronic stress increases VEGF secretion in TME, it can impair the efficacies of anti-angiogenic agents. By upregulating the VEGF expression via the $\beta$-AR-cAMP-PKA signaling pathway, chronic stress and exogenous norepinephrine markedly weakened the efficacy of sunitinib in rodent models of colorectal cancer and melanoma respectively (Deng et al., 2014; Liu et al., 2015).

Chronic stress-induced stress hormone norepinephrine (NE) promotes afatinib resistance by upregulating Cx32 expression which could decrease the degradation of EGFR-TKI resistanceassociated proteins (MET, IGF-1R) and increase their transcription levels (Xie et al., 2019). $\beta 2-\mathrm{AR}$ activation on non-small cell lung cancer (NSCLC) cell induces epidermal growth factor receptor (EGFR) tyrosine kinase inhibitor (TKI) resistance by inactivating liver kinase B1 (LKB1), elevating IL-6 expression, and MAPK pathway in a rodent model (Nilsson et al., 2017). Indeed, in treatment-naive patients with advanced lung adenocarcinoma receiving first-line EGFR-TKIs, prior b-blocker use was associated with a longer time-to-discontinuation (TTD) and overall survival (OS) (Chang et al., 2020).

\section{ANTI-CANCER TREATMENTS AND INTERVENTIONS TARGETING CHRONIC STRESS}

\section{$\beta$-Blocker}

$\beta$-blockers, such as propranolol and metoprolol, can block the interactions between catecholamine and $\beta$-AR, which inhibits the subsequent cancer-promoting effects induced by $\beta$-AR signaling as mentioned above (Fumagalli et al., 2020). Blocking $\beta$-AR interrupts the differentiation of exhausted $\mathrm{T}$ progenitors and 
decreases the number of exhausted T cells in TME (Qiao et al., 2021). Propranolol reduced MDSC accumulation in the TME of thermal-stressed mice treatments and controlled tumor growth (MacDonald et al., 2021). Blocking $\beta$-AR also increases glycolysis and oxidative phosphorylation in tumor-infiltrating lymphocytes (TIL), which leads to increased CD28 expression and enhanced anti-tumor functions (Qiao et al., 2021). Propranolol can enhance the sensitivity of gastric cancer cells to radiation in vitro by inhibiting NF- $\kappa \mathrm{B}-\mathrm{VEGF} / \mathrm{EGFR} / \mathrm{COX}-2$ pathway (Liao et al., 2010).

Combined administration of propranolol and etodolac, a cyclooxygenase- 2 inhibitor, improved the survival rate of mice with melanoma or Lewis lung carcinoma (Glasner et al., 2010). A prospective pilot study showed that the combination of propranolol with chemotherapy improved the quality of life (QOL) of patients with epithelial ovarian cancer (Ramondetta et al., 2019).

The combination of propranolol with targeted therapy may improve the efficacy. An exploratory analysis of the LUXLung3 study revealed a significant PFS prolongation of NSCLC patients taking $\beta$-blockers with EGFR-TKI afatinib compared with those taking afatinib alone (median $11.1 \mathrm{vs.}$ 6.9 months, $p=0.0001$ ), indicating there is a synergic effect combining $\beta$-blockers with anti-EGFR therapy (Nilsson et al., 2017).

As the favorable efficacy of immunotherapy is based on the premise of an immune-supportive TME, $\beta$-blockers may be ideal companions for immunotherapy owing to their capacity of inhibiting $\beta$-AR-induced TME deterioration. The increased density of CTLs and decreased expression of PD-1 induced by propranolol enhanced the efficacy of anti-PD-1 agents in a rodent model. Propranolol strongly improved the efficacy of an anti-tumor STxBE7 vaccine by enhancing the frequency of CTLs in a rodent model (Daher et al., 2019). Propranolol increased the concentration of IL-12, IL-17, 1L-2, and IFN- $\gamma$ in the breast tumor of mice and assisted with a tumor lysate vaccine (Ashrafi et al., 2017). A phase I study showed promising safety and activity of combining propranolol and pembrolizumab in the first-line treatment of metastatic melanoma (Gandhi et al., 2021). A meta-analysis revealed that $\beta$-blockers significantly improved DFS (HR 0.03, 95\% CI $0.01-0.17$ ) and OS (HR 0.04, 95\% CI 0.00-0.38) in melanoma patients, but the beneficial effect is quite tumor-specific (Yap et al., 2018).

\section{a-Blocker}

a-blockers can also function as anti-cancer agents. Quinazoline $\alpha-1$ blockers, such as prazosin, doxazosin, and terazosin, have shown promising anti-cancer effects in various types of cancer, and benefit chemotherapy, radiotherapy, and anti-EGFR therapy (Ashrafi et al., 2017). The VEGF-induced angiogenesis is inhibited by an $\alpha$-blocker, doxazosin, in human umbilical vein endothelial cells (Keledjian et al., 2005). Another selective a1-blocker, naftopidil, presents with antiproliferative and cytotoxic effects on prostate cancer as well as several other cancer types in vitro, ex vivo, and in vivo (Florent et al., 2020).

\section{Stress-Reducing Interventions}

Moreover, interventions targeting directly on physical or psychological stressors may ameliorate the TME and benefit anti-cancer treatments as well. The activation of the brain reward system decreased SNS activity and $\beta$-adrenergic signaling, which led to less immunosuppressive MDSCs in a murine model (Ben-Shaanan et al., 2018). Thermal treatments, including weekly whole-body hyperthermia and housing mice at their thermoneutral or sub-thermoneutral temperature, also decreased MDSC accumulation and tumor growth of mice (MacDonald et al., 2021). A similar enhancement of immune checkpoint inhibitor efficacy was observed in a rodent model with physiologically reduced stress (Bucsek et al., 2017). Mice housed in an enriched environment displayed enhanced NK-cell activity and increased infiltration of NK cells into TME (Song et al., 2017). Stress-reducing approaches, such as yoga, mindfulness, and cognitive behavioral therapy, have shown broad clinical benefits of increasing proportions of anti-tumor immune cells and cytokines in several studies, yet the results of these studies were limited with small sample sizes and short follow-ups (Antoni and Dhabhar, 2019).

\section{Others}

Additionally, a variety of other drugs may also reverse the unfavorable TME alterations in terms of chronic stress. Zoledronic acid, an anti-cancer adjuvant drug, is proficient in abrogating stress-induced macrophage infiltration, and PDGF-AA expression in a rodent ovarian cancer model (Colon-Echevarria et al., 2020). Antidepressants, such as fluoxetine and sertraline, can also alleviate chronic stress and have the potential in associating with cancer treatments, which still need further clinical confirmation (Di Rosso et al., 2018).

Some other strategies targeting chronic stress-inducible inflammatory signaling have shown promising efficacies in clinical practice. Bevacizumab, an anti-VEGF agent, is now applicable for a wide range of solid tumors and has shown favorable efficacies combined with chemotherapy, immune checkpoint inhibitors, anti-EGFR therapy, and PARP inhibitors (Garcia et al., 2020). Anti-IL-6 or Anti-IL-6 receptor agents, such as tocilizumab and siltuximab, have not shown satisfactory efficacies in cancers (Rossi et al., 2015), yet tocilizumab has been widely used to treat cytokine release syndrome induced by CAR T-cell toxicity (Brudno and Kochenderfer, 2019).

\section{DISCUSSION}

In summary, the TME under chronic stress is differentiated from others by increased numbers and enhanced functions of immunosuppressive cells, decreased amounts and impaired functions of immunosupportive cells, associated with corresponding changes in cytokines, which results in intense angiogenesis, boosted tumor cell proliferation and enhanced EMT inside of the TME. The over-secretion of glucocorticoid and catecholamines deriving from persistent activations of the 
HPA axis and SNS mostly contribute to the TME alterations under chronic stress. These alterations can reduce the efficacies of anti-tumor therapies, like chemotherapy, immunotherapy, and targeted therapy. Drugs, such as $\alpha$-blockers, $\beta$-blockers, antidepressants, and interventions, like meditation and mindfulness, may cut down the negative effects of chronic stress, which should draw the attention of clinical oncologists in adopting treatment plans for patients with chronic stress.

Still, recent studies for the interactions of chronic stress and TME have limitations, such as absences of evaluation of animal stress levels within the group and assessments for stress levels before investigations in animal models (Hylander et al., 2019). Therefore, researchers should value the importance of stress quantification in research, and approaches, such as detections of serum glucocorticoids and catecholamines before further procedures, should be taken to control potential bias.

\section{AUTHOR CONTRIBUTIONS}

WT searched for the literature and wrote the original draft; YL helped write a part of the manuscript; CC processed the images; YZ, YPA, XL, and YPE revised the whole manuscript; FW

\section{REFERENCES}

Acharya, N., Madi, A., Zhang, H., Klapholz, M., Escobar, G., Dulberg, S., et al. (2020). Endogenous Glucocorticoid Signaling Regulates CD8+ T Cell Differentiation and Development of Dysfunction in the Tumor Microenvironment. Immunity. 53 (3), 658-671. e656. doi:10.1016/j.immuni.2020.08.005

Aggarwal, S., Gabrovsek, L., Langeberg, L. K., Golkowski, M., Ong, S.-E., Smith, F. D., et al. (2019). Depletion of dAKAP1-Protein Kinase A Signaling Islands From the Outer Mitochondrial Membrane Alters Breast Cancer Cell Metabolism and Motility. J. Biol. Chem. 294 (9), 3152-3168. doi:10.1074/ jbc.RA118.006741

Antoni, M. H., and Dhabhar, F. S. (2019). The Impact of Psychosocial Stress and Stress Management on Immune Responses in Patients With Cancer. Cancer. 125 (9), 1417-1431. doi:10.1002/cncr.31943

Ashrafi, S., Shapouri, R., and Mahdavi, M. (2017). Immunological Consequences of Immunization With Tumor Lysate Vaccine and Propranolol as an Adjuvant: A Study on Cytokine Profiles in Breast Tumor Microenvironment. Immunol. Lett. 181, 63-70. doi:10.1016/j.imlet.2016.11.014

Baghban, R., Roshangar, L., Jahanban-Esfahlan, R., Seidi, K., Ebrahimi-Kalan, A., Jaymand, M., et al. (2020). Tumor Microenvironment Complexity and Therapeutic Implications at a Glance. Cell Commun Signal. 18 (1), 59. doi:10.1186/s12964-020-0530-4

Ben-Eliyahu, S., Page, G. G., Yirmiya, R., and Shakhar, G. (1999). Evidence that Stress and Surgical Interventions Promote Tumor Development by Suppressing Natural Killer Cell Activity. Int. J. Cancer. 80 (6), 880-888. doi:10.1002/(sici) 1097-0215(19990315)80:6<880:aid-ijc14>3.0.co;2-y

Ben-Shaanan, T. L., Schiller, M., Azulay-Debby, H., Korin, B., Boshnak, N., Koren, T., et al. (2018). Modulation of Anti-Tumor Immunity by the Brain's Reward System. Nat. Commun. 9 (1), 2723. doi:10.1038/s41467-018-05283-5

Biazi, G. R., Frasson, I. G., Miksza, D. R., de Morais, H., de Fatima Silva, F., Bertolini, G. L., et al. (2018). Decreased Hepatic Response to Glucagon, Adrenergic Agonists, and CAMP in Glycogenolysis, Gluconeogenesis, and Glycolysis in Tumor-Bearing Rats. J. Cell Biochem. 119 (9), 7300-7309. doi:10.1002/jcb.27027

Brudno, J. N., and Kochenderfer, J. N. (2019). Recent Advances in CAR T-Cell Toxicity: Mechanisms, Manifestations and Management. Blood Rev. 34, 45-55. doi:10.1016/j.blre.2018.11.002 contributed to the conception of the review, and supervised the whole process of this work.

\section{FUNDING}

This work was supported by: 1) Natural Science Foundation of Hunan Province for Excellent Young Scholars (Grant No. 2021JJ20088); 2) Beijing Xisike Clinical Oncology Research Foundation (Grant No. Y-HS202102-0130); 3) Guangdong Association of Clinical Trials (GACT) /Chinese Thoracic Oncology Group (CTONG); 4) Guangdong Provincial Key Lab of Translational Medicine in Lung Cancer (Grant No. 2017B030314120); 5) Changsha Science and Technology Bureau (Grant No. kq1907077).

\section{ACKNOWLEDGMENTS}

The authors would like to thank the multi-disciplinary team (MDT) for thoracic tumors of the Second Xiangya Hospital of Central South University for the inspiration and guidance of this paper.

Bruzzone, A., Perez Pinero, C., Rojas, P., Romanato, M., Gass, H., Lanari, C., et al. (2011). a2-Adrenoceptors Enhance Cell Proliferation and Mammary Tumor Growth Acting Through Both the Stroma and the Tumor Cells. Curr. Cancer Drug. Targets. 11 (6), 763-774. doi:10.2174/ 156800911796191051

Bucsek, M. J., Qiao, G., MacDonald, C. R., Giridharan, T., Evans, L., Niedzwecki, B., et al. (2017). $\beta$-Adrenergic Signaling in Mice Housed at Standard Temperatures Suppresses an Effector Phenotype in CD8+ T Cells and Undermines Checkpoint Inhibitor Therapy. Cancer Res. 77 (20), 5639-5651. doi:10.1158/ 0008-5472.CAN-17-0546

Calvani, M., Dabraio, A., Subbiani, A., Buonvicino, D., De Gregorio, V., Ciullini Mannurita, S., et al. (2020). ß3-Adrenoceptors as Putative Regulator of Immune Tolerance in Cancer and Pregnancy. Front. Immunol. 11, 2098. doi:10.3389/ fimmu.2020.02098

Chang, C.-H., Lee, C.-H., Ko, J.-C., Chang, L.-Y., Lee, M.-C., Zhang, J.-F., et al. (2020). Effect of $\beta$-Blocker in Treatment-Naïve Patients With Advanced Lung Adenocarcinoma Receiving First-Generation EGFR-TKIs. Front. Oncol. 10, 583529. doi:10.3389/fonc.2020.583529

Chen, X., and Song, E. (2019). Turning Foes to Friends: Targeting CancerAssociated Fibroblasts. Nat. Rev. Drug Discov. 18 (2), 99-115. doi:10.1038/ s41573-018-0004-1

Chen, Y.-X., Wang, Y., Fu, C.-C., Diao, F., Song, L.-N., Li, Z.-B., et al. (2010). Dexamethasone Enhances Cell Resistance to Chemotherapy by Increasing Adhesion to Extracellular Matrix in Human Ovarian Cancer Cells. Endocr. Relat. Cancer. 17 (1), 39-50. doi:10.1677/ERC-08-0296

Chen, Z., Lan, X., Wu, D., Sunkel, B., Ye, Z., Huang, J., et al. (2015). LigandDependent Genomic Function of Glucocorticoid Receptor in Triple-Negative Breast Cancer. Nat. Commun. 6, 8323. doi:10.1038/ncomms9323

Cheng, Y., Tang, X.-Y., Li, Y.-X., Zhao, D.-D., Cao, Q.-H., Wu, H.-X., et al. (2019). Depression-Induced Neuropeptide Y Secretion Promotes Prostate Cancer Growth by Recruiting Myeloid Cells. Clin. Cancer Res. 25 (8), 2621-2632. doi:10.1158/1078-0432.CCR-18-2912

Chiarugi, P., and Filippi, L. (2015). $\beta 3$-Adrenoreceptor and Tumor Microenvironment: a New Hub. Oncoimmunology. 4 (11), e1026532. doi:10.1080/2162402X.2015.1026532

Chida, Y., Hamer, M., Wardle, J., and Steptoe, A. (2008). Do Stress-Related Psychosocial Factors Contribute to Cancer Incidence and Survival? Nat. Rev. Clin. Oncol. 5 (8), 466-475. doi:10.1038/ncponc1134 
Cole, S. W., and Sood, A. K. (2012). Molecular Pathways: Beta-Adrenergic Signaling in Cancer: Figure 1. Clin. Cancer Res. 18 (5), 1201-1206. doi:10.1158/1078-0432.CCR-11-0641

Colon-Echevarria, C. B., Ortiz, T., Maldonado, L., Hidalgo-Vargas, M. J., PérezMorales, J., Aquino-Acevedo, A. N., et al. (2020). Zoledronic Acid Abrogates Restraint Stress-Induced Macrophage Infiltration, PDGF-AA Expression, and Ovarian Cancer Growth. Cancers. 12 (9), 2671. doi:10.3390/cancers12092671

Cui, B., Luo, Y., Tian, P., Peng, F., Lu, J., Yang, Y., et al. (2019). Stress-Induced Epinephrine Enhances Lactate Dehydrogenase A and Promotes Breast Cancer Stem-Like Cells. J. Clin. Invest. 129 (3), 1030-1046. doi:10.1172/JCI121685

Daher, C., Vimeux, L., Stoeva, R., Peranzoni, E., Bismuth, G., Wieduwild, E., et al. (2019). Blockade of $\beta$-Adrenergic Receptors Improves CD8+ T-Cell Priming and Cancer Vaccine Efficacy. Cancer Immunol. Res. 7 (11), 1849-1863. doi:10.1158/2326-6066.CIR-18-0833

Daly, C. J., and McGrath, J. C. (2011). Previously Unsuspected Widespread Cellular and Tissue Distribution of $\beta$-Adrenoceptors and its Relevance to Drug Action. Trends Pharmacol. Sci. 32 (4), 219-226. doi:10.1016/j.tips.2011.02.008

DeNardo, D. G., and Ruffell, B. (2019). Macrophages as Regulators of Tumour Immunity and Immunotherapy. Nat. Rev. Immunol. 19 (6), 369-382. doi:10.1038/s41577-019-0127-6

Deng, G.-H., Liu, J., Zhang, J., Wang, Y., Peng, X.-C., Wei, Y.-Q., et al. (2014). Exogenous Norepinephrine Attenuates the Efficacy of Sunitinib in a Mouse Cancer Model. J. Exp. Clin. Cancer Res. 33, 21. doi:10.1186/1756-9966-33-21

Di Rosso, M. E., Sterle, H. A., Cremaschi, G. A., and Genaro, A. M. (2018). Beneficial Effect of Fluoxetine and Sertraline on Chronic Stress-Induced Tumor Growth and Cell Dissemination in a Mouse Model of Lymphoma: Crucial Role of Antitumor Immunity. Front. Immunol. 9, 1341. doi:10.3389/ fimmu.2018.01341

Du, P., Zeng, H., Xiao, Y., Zhao, Y., Zheng, B., Deng, Y., et al. (2020). Chronic Stress Promotes EMT-Mediated Metastasis Through Activation of STAT3 Signaling Pathway by miR-337-3p in Breast Cancer. Cell Death Dis. 11 (9), 761. doi:10.1038/s41419-020-02981-1

Duan, M., Goswami, S., Shi, J.-Y., Wu, L.-J., Wang, X.-Y., Ma, J.-Q., et al. (2019). Activated and Exhausted MAIT Cells Foster Disease Progression and Indicate Poor Outcome in Hepatocellular Carcinoma. Clin. Cancer Res. 25 (11), 3304-3316. doi:10.1158/1078-0432.ccr-18-3040

Durkee, C. A., Covelo, A., Lines, J., Kofuji, P., Aguilar, J., and Araque, A. (2019). G I/o Protein-Coupled Receptors Inhibit Neurons but Activate Astrocytes and Stimulate Gliotransmission. Glia. 67 (6), 1076-1093. doi:10.1002/glia.23589

Fan, K.-q., Li, Y.-y., Wang, H.-1., Mao, X.-t., Guo, J.-x., Wang, F., et al. (2019). Stress-Induced Metabolic Disorder in Peripheral CD4+ T Cells Leads to Anxiety-Like Behavior. Cell. 179 (4), 864-879. doi:10.1016/j.cell.2019.10.001

Florent, R., Poulain, L., and N'Diaye, M. (2020). Drug Repositioning of the a1Adrenergic Receptor Antagonist Naftopidil: A Potential New Anti-Cancer Drug? Int. J. Mol. Sci. 21 (15), 5339. doi:10.3390/ijms21155339

Fumagalli, C., Maurizi, N., Marchionni, N., and Fornasari, D. (2020). $\beta$-Blockers: Their New Life From Hypertension to Cancer and Migraine. Pharmacol. Res. 151, 104587. doi:10.1016/j.phrs.2019.104587

Gabrilovich, D. I. (2017). Myeloid-Derived Suppressor Cells. Cancer Immunol. Res. 5 (1), 3-8. doi:10.1158/2326-6066.CIR-16-0297

Gandhi, S., Pandey, M. R., Attwood, K., Ji, W., Witkiewicz, A. K., Knudsen, E. S., et al. (2021). Phase I Clinical Trial of Combination Propranolol and Pembrolizumab in Locally Advanced and Metastatic Melanoma: Safety, Tolerability, and Preliminary Evidence of Antitumor Activity. Clin. Cancer Res. 27 (1), 87-95. doi:10.1158/1078-0432.CCR-20-2381

Gao, X., Cao, Q., Cheng, Y., Zhao, D., Wang, Z., Yang, H., et al. (2018). Chronic Stress Promotes Colitis by Disturbing the Gut Microbiota and Triggering Immune System Response. Proc. Natl. Acad. Sci. USA. 115 (13), E2960-E2969. doi:10.1073/pnas.1720696115

Garcia, J., Hurwitz, H. I., Sandler, A. B., Miles, D., Coleman, R. L., Deurloo, R., et al. (2020). Bevacizumab (Avastin) in Cancer Treatment: A Review of 15 Years of Clinical Experience and Future Outlook. Cancer Treat. Rev. 86, 102017. doi:10.1016/j.ctrv.2020.102017

Gardner, A., and Ruffell, B. (2016). Dendritic Cells and Cancer Immunity. Trends Immunol. 37 (12), 855-865. doi:10.1016/j.it.2016.09.006

Gil, F., Costa, G., Hilker, I., and Benito, L. (2012). First Anxiety, Afterwards Depression: Psychological Distress in Cancer Patients at Diagnosis and After Medical Treatment. Stress and Health. 28 (5), 362-367. doi:10.1002/smi.2445
Glasner, A., Avraham, R., Rosenne, E., Benish, M., Zmora, O., Shemer, S., et al. (2010). Improving Survival Rates in Two Models of Spontaneous Postoperative Metastasis in Mice by Combined Administration of a $\beta$-Adrenergic Antagonist and a Cyclooxygenase-2 Inhibitor. J.I. 184 (5), 2449-2457. doi:10.4049/ jimmunol.0903301

Guereschi, M. G., Araujo, L. P., Maricato, J. T., Takenaka, M. C., Nascimento, V. M., Vivanco, B. C., et al. (2013). Beta2-Adrenergic Receptor Signaling in CD4+Foxp3+Regulatory T Cells Enhances Their Suppressive Function in a PKA-Dependent Manner. Eur. J. Immunol. 43 (4), 1001-1012. doi:10.1002/ eji.201243005

Hara, M. R., Kovacs, J. J., Whalen, E. J., Rajagopal, S., Strachan, R. T., Grant, W., et al. (2011). A Stress Response Pathway Regulates DNA Damage through $\beta 2$ Adrenoreceptors and $\beta$-Arrestin-1. Nature. 477 (7364), 349-353. doi:10.1038/ nature 10368

Hulsurkar, M., Li, Z., Zhang, Y., Li, X., Zheng, D., and Li, W. (2017). BetaAdrenergic Signaling Promotes Tumor Angiogenesis and Prostate Cancer Progression through HDAC2-Mediated Suppression of Thrombospondin-1. Oncogene. 36 (11), 1525-1536. doi:10.1038/onc.2016.319

Hylander, B. L., Gordon, C. J., and Repasky, E. A. (2019). Manipulation of Ambient Housing Temperature To Study the Impact of Chronic Stress on Immunity and Cancer in Mice. J.I. 202 (3), 631-636. doi:10.4049/jimmunol.1800621

Kadmiel, M., and Cidlowski, J. A. (2013). Glucocorticoid Receptor Signaling in Health and Disease. Trends Pharmacol. Sci. 34 (9), 518-530. doi:10.1016/ j.tips.2013.07.003

Kang, Y., Nagaraja, A. S., Armaiz-Pena, G. N., Dorniak, P. L., Hu, W., Rupaimoole, R., et al. (2016). Adrenergic Stimulation of DUSP1 Impairs Chemotherapy Response in Ovarian Cancer. Clin. Cancer Res. 22 (7), 1713-1724. doi:10.1158/ 1078-0432.Ccr-15-1275

Keledjian, K., Garrison, J. B., and Kyprianou, N. (2005). Doxazosin Inhibits Human Vascular Endothelial Cell Adhesion, Migration, and Invasion. J. Cell. Biochem. 94 (2), 374-388. doi:10.1002/jcb.20240

Kerbel, R. S. (2008). Tumor Angiogenesis. N. Engl. J. Med. 358 (19), 2039-2049. doi:10.1056/NEJMra0706596

Lamouille, S., Xu, J., and Derynck, R. (2014). Molecular Mechanisms of EpithelialMesenchymal Transition. Nat. Rev. Mol. Cell Biol. 15 (3), 178-196. doi:10.1038/ nrm3758

Li, N., Du, Z.-X., Zong, Z.-H., Liu, B.-Q., Li, C., Zhang, Q., et al. (2013). PkcסMediated Phosphorylation of BAG3 at Ser187 Site Induces Epithelial-Mesenchymal Transition and Enhances Invasiveness in Thyroid Cancer FRO Cells. Oncogene. 32 (38), 4539-4548. doi:10.1038/onc.2012.466

Liao, X., Che, X., Zhao, W., Zhang, D., Long, H., Chaudhary, P., et al. (2010). Effects of Propranolol in Combination with Radiation on Apoptosis and Survival of Gastric Cancer Cells In Vitro. Radiat. Oncol. 5, 98. doi:10.1186/1748-717X-5-98

Liu, J., Deng, G.-H., Zhang, J., Wang, Y., Xia, X.-Y., Luo, X.-M., et al. (2015). The Effect of Chronic Stress on Anti-angiogenesis of Sunitinib in Colorectal Cancer Models. Psychoneuroendocrinology. 52, 130-142. doi:10.1016/ j.psyneuen.2014.11.008

Liu, L., Lei, B., Wang, L., Chang, C., Yang, H., Liu, J., et al. (2019). Protein Kinase C-Iota-Mediated Glycolysis Promotes Non-Small-Cell Lung Cancer Progression. Onco Targets Ther. 12, 5835-5848. doi:10.2147/OTT.S207211

Lutgendorf, S. K., Lamkin, D. M., Jennings, N. B., Arevalo, J. M. G., Penedo, F., DeGeest, K., et al. (2008). Biobehavioral Influences on Matrix Metalloproteinase Expression in Ovarian Carcinoma. Clin. Cancer Res. 14 (21), 6839-6846. doi:10.1158/1078-0432.CCR-08-0230

Lutgendorf, S. K., Sood, A. K., Anderson, B., McGinn, S., Maiseri, H., Dao, M., et al. (2005). Social Support, Psychological Distress, and Natural Killer Cell Activity in Ovarian Cancer. J. Clin. Oncol. 23 (28), 7105-7113. doi:10.1200/ JCO.2005.10.015

Ma, X., Wang, M., Yin, T., Zhao, Y., and Wei, X. (2019). Myeloid-Derived Suppressor Cells Promote Metastasis in Breast Cancer After the Stress of Operative Removal of the Primary Cancer. Front. Oncol. 9, 855. doi:10.3389/fonc.2019.00855

MacDonald, C., Ministero, S., Pandey, M., Robinson, D., Forti Hong, E., Hylander, B., et al. (2021). Comparing thermal Stress Reduction Strategies that Influence MDSC Accumulation in Tumor Bearing Mice. Cell Immunol. 361, 104285. doi:10.1016/j.cellimm.2021.104285

Matyszak, M. K., Citterio, S., Rescigno, M., and Ricciardi-Castagnoli, P. (2000). Differential Effects of Corticosteroids During Different Stages of Dendritic Cell 
Maturation. Eur. J. Immunol. 30 (4), 1233-1242. doi:10.1002/(sici)15214141(200004)30:4<1233:aid-immu1233>3.0.co;2-f

Mravec, B., Tibensky, M., and Horvathova, L. (2020). Stress and Cancer. Part II: Therapeutic Implications for Oncology. J. Neuroimmunology. 346, 577312. doi:10.1016/j.jneuroim.2020.577312

Muthuswamy, R., Okada, N. J., Jenkins, F. J., McGuire, K., McAuliffe, P. F., Zeh, H. J., et al. (2017). Epinephrine Promotes COX-2-Dependent Immune Suppression in Myeloid Cells and Cancer Tissues. Brain Behav. Immun. 62, 78-86. doi:10.1016/j.bbi.2017.02.008

Nadella, K. S., Jones, G. N., Trimboli, A., Stratakis, C. A., Leone, G., and Kirschner, L. S. (2008). Targeted Deletion of Prkarla Reveals a Role for Protein Kinase A in Mesenchymal-To-Epithelial Transition. Cancer Res. 68 (8), 2671-2677. doi:10.1158/0008-5472.CAN-07-6002

Najafi, M., Farhood, B., and Mortezaee, K. (2019). Extracellular Matrix (ECM) Stiffness and Degradation as Cancer Drivers. J. Cell Biochem. 120 (3), 2782-2790. doi:10.1002/jcb.27681

Neri, D., and Supuran, C. T. (2011). Interfering With pH Regulation in Tumours as a Therapeutic Strategy. Nat. Rev. Drug Discov. 10 (10), 767-777. doi:10.1038/ $\operatorname{nrd} 3554$

Nilsson, M. B., Sun, H., Diao, L., Tong, P., Liu, D., Li, L., et al. (2017). Stress Hormones Promote EGFR Inhibitor Resistance in NSCLC: Implications for Combinations With $\beta$-blockers. Sci. Transl. Med. 9 (415), eaao4307. doi:10.1126/scitranslmed.aao4307

Pattabiraman, D. R., Bierie, B., Kober, K. I., Thiru, P., Krall, J. A., Zill, C., et al. (2016). Activation of PKA Leads to Mesenchymal-To-Epithelial Transition and Loss of Tumor-Initiating Ability. Science. 351 (6277), aad3680. doi:10.1126/ science.aad 3680

Pearce, E. L., Poffenberger, M. C., Chang, C.-H., and Jones, R. G. (2013). Fueling Immunity: Insights into Metabolism and Lymphocyte Function. Science. 342 (6155), 1242454. doi:10.1126/science.1242454

Picard, M., and McEwen, B. S. (2018). Psychological Stress and Mitochondria: A Systematic Review. Psychosom Med. 80 (2), 141-153. doi:10.1097/ PSY.0000000000000545

Powell, N. D., Tarr, A. J., and Sheridan, J. F. (2013). Psychosocial Stress and Inflammation in Cancer. Brain Behav. Immun. 30 (Suppl. 1), S41-S47. doi:10.1016/j.bbi.2012.06.015

Qiao, G., Chen, M., Mohammadpour, H., MacDonald, C. R., Bucsek, M. J., Hylander, B. L., et al. (2021). Chronic Adrenergic Stress Contributes to Metabolic Dysfunction and an Exhausted Phenotype in T Cells in the Tumor Microenvironment. Cancer Immunol. Res. 9, 651-664. doi:10.1158/ 2326-6066.CIR-20-0445

Qin, J.-f., Jin, F.-j., Li, N., Guan, H.-t., Lan, L., Ni, H., et al. (2015). Adrenergic Receptor $\beta 2$ Activation by Stress Promotes Breast Cancer Progression Through Macrophages M2 Polarization in Tumor Microenvironment. BMB Rep. 48 (5), 295-300. doi:10.5483/bmbrep.2015.48.5.008

Ramondetta, L. M., Hu, W., Thaker, P. H., Urbauer, D. L., Chisholm, G. B., Westin, S. N., et al. (2019). Prospective Pilot Trial With Combination of Propranolol With Chemotherapy in Patients With Epithelial Ovarian Cancer and Evaluation on Circulating Immune Cell Gene Expression. Gynecol. Oncol. 154 (3), 524-530. doi:10.1016/j.ygyno.2019.07.004

Reiche, E. M. V., Nunes, S. O. V., and Morimoto, H. K. (2004). Stress, Depression, the Immune System, and Cancer. Lancet Oncol. 5 (10), 617-625. doi:10.1016/ s1470-2045(04)01597-9

Rey, S., Schito, L., Wouters, B. G., Eliasof, S., and Kerbel, R. S. (2017). Targeting Hypoxia-Inducible Factors for Antiangiogenic Cancer Therapy. Trends Cancer. 3 (7), 529-541. doi:10.1016/j.trecan.2017.05.002

Roma-Rodrigues, C., Mendes, R., Baptista, P., and Fernandes, A. (2019). Targeting Tumor Microenvironment for Cancer Therapy. Int. J. Mol Sci. 20 (4), 840. doi:10.3390/ijms20040840

Rossi, J.-F., Lu, Z.-Y., Jourdan, M., and Klein, B. (2015). Interleukin-6 as a Therapeutic Target. Clin. Cancer Res. 21 (6), 1248-1257. doi:10.1158/10780432.CCR-14-2291

Saul, A. N., Oberyszyn, T. M., Daugherty, C., Kusewitt, D., Jones, S., Jewell, S., et al. (2005). Chronic Stress and Susceptibility to Skin Cancer. J. Natl. Cancer Inst. 97 (23), 1760-1767. doi:10.1093/jnci/dji401

Schmidt, D., Peterlik, D., Reber, S. O., Lechner, A., and Männel, D. N. (2016). Induction of Suppressor Cells and Increased Tumor Growth Following Chronic
Psychosocial Stress in Male Mice. PLoS One. 11 (7), e0159059. doi:10.1371/ journal.pone.0159059

Shaikh, D., Zhou, Q., Chen, T., Ibe, J. C. F., Raj, J. U., and Zhou, G. (2012). CAMPDependent Protein Kinase Is Essential for Hypoxia-Mediated EpithelialMesenchymal Transition, Migration, and Invasion in Lung Cancer Cells. Cell Signal. 24 (12), 2396-2406. doi:10.1016/j.cellsig.2012.08.007

Shan, T., Cui, X., Li, W., Lin, W., Li, Y., Chen, X., et al. (2014). Novel Regulatory Program for Norepinephrine-Induced Epithelial-Mesenchymal Transition in Gastric Adenocarcinoma Cell Lines. Cancer Sci. 105 (7), 847-856. doi:10.1111/ cas. 12438

Silverman, M. N., and Sternberg, E. M. (2012). Glucocorticoid Regulation of Inflammation and its Functional Correlates: from HPA axis to Glucocorticoid Receptor Dysfunction. Ann. N. Y Acad. Sci. 1261, 55-63. doi:10.1111/j.17496632.2012.06633.x

Sloan, E. K., Capitanio, J. P., Tarara, R. P., Mendoza, S. P., Mason, W. A., and Cole, S. W. (2007). Social Stress Enhances Sympathetic Innervation of Primate Lymph Nodes: Mechanisms and Implications for Viral Pathogenesis. J. Neurosci. 27 (33), 8857-8865. doi:10.1523/ JNEUROSCI.1247-07.2007

Sommershof, A., Scheuermann, L., Koerner, J., and Groettrup, M. (2017). Chronic Stress Suppresses Anti-tumor TCD8+ Responses and Tumor Regression Following Cancer Immunotherapy in a Mouse Model of Melanoma. Brain Behav. Immun. 65, 140-149. doi:10.1016/j.bbi.2017.04.021

Song, Y., Gan, Y., Wang, Q., Meng, Z., Li, G., Shen, Y., et al. (2017). Enriching the Housing Environment for Mice Enhances Their NK Cell Antitumor Immunity via Sympathetic Nerve-Dependent Regulation of NKG2D and CCR5. Cancer Res. 77 (7), 1611-1622. doi:10.1158/0008-5472.CAN-162143

Talts, J. F., Weller, A., Timpl, R., Ekblom, M., and Ekblom, P. (1995). Regulation of Mesenchymal Extracellular Matrix Protein Synthesis by Transforming Growth Factor-Beta and Glucocorticoids in Tumor Stroma. J. Cell Sci. 108 ( Pt 6) (Pt 6), 2153-2162. doi:10.1242/jcs.108.6.2153

Tam, W. L., Lu, H., Buikhuisen, J., Soh, B. S., Lim, E., Reinhardt, F., et al. (2013). Protein Kinase $\mathrm{C}$ a Is a Central Signaling Node and Therapeutic Target for Breast Cancer Stem Cells. Cancer Cell. 24 (3), 347-364. doi:10.1016/ j.ccr.2013.08.005

Taylor, B. N., and Cassagnol, M. (2021). "Alpha Adrenergic Receptors," in StatPearls. (Treasure Island (FL): StatPearls Publishing Copyright (๑) 2021, StatPearls Publishing LLC).

Thaker, P. H., Han, L. Y., Kamat, A. A., Arevalo, J. M., Takahashi, R., Lu, C., et al. (2006). Chronic Stress Promotes Tumor Growth and Angiogenesis in a Mouse Model of Ovarian Carcinoma. Nat. Med. 12 (8), 939-944. doi:10.1038/nm1447

Thommen, D. S., and Schumacher, T. N. (2018). T Cell Dysfunction in Cancer. Cancer Cell. 33 (4), 547-562. doi:10.1016/j.ccell.2018.03.012

Timmermans, S., Souffriau, J., and Libert, C. (2019). A General Introduction to Glucocorticoid Biology. Front. Immunol. 10, 1545. doi:10.3389/ fimmu.2019.01545

Varker, K. A., Terrell, C. E., Welt, M., Suleiman, S., Thornton, L., Andersen, B. L., et al. (2007). Impaired Natural Killer Cell Lysis in Breast Cancer Patients With High Levels of Psychological Stress Is Associated with Altered Expression of Killer Immunoglobin-like Receptors. J. Surg. Res. 139 (1), 36-44. doi:10.1016/ j.jss.2006.08.037

Vergara, D., Ravaioli, S., Fonzi, E., Adamo, L., Damato, M., Bravaccini, S., et al. (2020). Carbonic Anhydrase XII Expression Is Modulated During Epithelial Mesenchymal Transition and Regulated Through Protein Kinase C Signaling. Int. J. Mol Sci. 21 (3), 715. doi:10.3390/ijms 21030715

Vergara, D., Simeone, P., Damato, M., Maffia, M., Lanuti, P., and Trerotola, M. (2019). The Cancer Microbiota: EMT and Inflammation as Shared Molecular Mechanisms Associated With Plasticity and Progression. J. Oncol. 2019, 1-16. doi:10.1155/2019/1253727

Wu, X., Liu, B.-J., Ji, S., Wu, J.-F., Xu, C.-Q., Du, Y.-J., et al. (2015). Social Defeat Stress Promotes Tumor Growth and Angiogenesis by Upregulating Vascular Endothelial Growth Factor/Extracellular Signal-Regulated Kinase/Matrix Metalloproteinase Signaling in a Mouse Model of Lung Carcinoma. Mol. Med. Rep. 12 (1), 1405-1412. doi:10.3892/mmr.2015.3559

Xie, H., Li, C., He, Y., Griffin, R., Ye, Q., and Li, L. (2015). Chronic Stress Promotes Oral Cancer Growth and Angiogenesis with Increased Circulating 
Catecholamine and Glucocorticoid Levels in a Mouse Model. Oral Oncol. 51 (11), 991-997. doi:10.1016/j.oraloncology.2015.08.007

Xie, J., Wang, X., Ge, H., Peng, F., Zheng, N., Wang, Q., et al. (2019). Cx32 Mediates Norepinephrine-Promoted EGFR-TKI Resistance in a Gap JunctionIndependent Manner in Non-Small-Cell Lung Cancer. J. Cell Physiol. 234 (12), 23146-23159. doi:10.1002/jcp.28881

Yang, E. V., Kim, S.-j., Donovan, E. L., Chen, M., Gross, A. C., Webster Marketon, J. I., et al. (2009). Norepinephrine Upregulates VEGF, IL-8, and IL-6 Expression in Human Melanoma Tumor Cell Lines: Implications for Stress-Related Enhancement of Tumor Progression. Brain Behav. Immun. 23 (2), 267-275. doi:10.1016/j.bbi.2008.10.005

Yang, E. V., Sood, A. K., Chen, M., Li, Y., Eubank, T. D., Marsh, C. B., et al. (2006a). Norepinephrine Up-Regulates the Expression of Vascular Endothelial Growth Factor, Matrix Metalloproteinase (MMP)-2, and MMP-9 in Nasopharyngeal Carcinoma Tumor Cells. Cancer Res. 66 (21), 10357-10364. doi:10.1158/00085472.CAN-06-2496

Yang, Y., Pan, X., Lei, W., Wang, J., Shi, J., Li, F., et al. (2006b). Regulation of Transforming Growth Factor- $\beta 1$-Induced Apoptosis and Epithelial-To-Mesenchymal Transition by Protein Kinase A and Signal Transducers and Activators of Transcription 3. Cancer Res. 66 (17), 8617-8624. doi:10.1158/0008-5472.CAN-06-1308

Yang, H., Xia, L., Chen, J., Zhang, S., Martin, V., Li, Q., et al. (2019). StressGlucocorticoid-TSC22D3 Axis Compromises Therapy-Induced Antitumor Immunity. Nat. Med. 25 (9), 1428-1441. doi:10.1038/s41591-019-0566-4

Yap, A., Lopez-Olivo, M. A., Dubowitz, J., Pratt, G., Hiller, J., Gottumukkala, V., et al. (2018). Effect of Beta-Blockers on Cancer Recurrence and Survival: a Meta-Analysis of Epidemiological and Perioperative Studies. Br. J. Anaesth. 121 (1), 45-57. doi:10.1016/j.bja.2018.03.024

Zafar, A., Hardy, K., Wu, F., Li, J., and Rao, S. (2015). The Role of Protein Kinase-C Theta in Control of Epithelial to Mesenchymal Transition and Cancer Stem Cell Formation. Genomics Data. 3, 28-32. doi:10.1016/j.gdata.2014.11.002

Zafar, A., Wu, F., Hardy, K., Li, J., Tu, W. J., McCuaig, R., et al. (2014). Chromatinized Protein Kinase C- $\theta$ Directly Regulates Inducible Genes in Epithelial to Mesenchymal Transition and Breast Cancer Stem Cells. Mol. Cell Biol. 34 (16), 2961-2980. doi:10.1128/MCB.01693-13

Zahalka, A. H., Arnal-Estapé, A., Maryanovich, M., Nakahara, F., Cruz, C. D., Finley, L. W. S., et al. (2017). Adrenergic Nerves Activate an Angio-Metabolic
Switch in Prostate Cancer. Science. 358 (6361), 321-326. doi:10.1126/ science.aah5072

Zhang, J., Deng, Y.-t., Liu, J., Wang, Y.-q., Yi, T.-w., Huang, B.-y., et al. (2016). Norepinephrine Induced Epithelial-Mesenchymal Transition in HT-29 and A549 Cells In Vitro. J. Cancer Res. Clin. Oncol. 142 (2), 423-435. doi:10.1007/ s00432-015-2044-9

Zhang, L., Pan, J., Chen, W., Jiang, J., and Huang, J. (2020). Chronic StressInduced Immune Dysregulation in Cancer: Implications for Initiation, Progression, Metastasis, and Treatment. Am. J. Cancer Res. 10 (5), 1294-1307.

Zhou, J., Liu, Z., Zhang, L., Hu, X., Wang, Z., Ni, H., et al. (2020). Activation of $\beta 2$ Adrenergic Receptor Promotes Growth and Angiogenesis in Breast Cancer by Down-Regulating PPAR $\gamma$. Cancer Res. Treat. 52 (3), 830-847. doi:10.4143/ crt.2019.510

Zhou, Q., Qian, Z., Ding, W., Jiang, G., Sun, C., and Xu, K. (2021). Chronic Psychological Stress Attenuates the Efficacy of Anti-PD-L1 Immunotherapy for Bladder Cancer in Immunocompetent Mice. Cancer Invest. 39 (6-7), 571-581. doi:10.1080/07357907.2021.1943746

Conflict of Interest: The authors declare that the research was conducted in the absence of any commercial or financial relationships that could be construed as a potential conflict of interest.

Publisher's Note: All claims expressed in this article are solely those of the authors and do not necessarily represent those of their affiliated organizations, or those of the publisher, the editors and the reviewers. Any product that may be evaluated in this article, or claim that may be made by its manufacturer, is not guaranteed or endorsed by the publisher.

Copyright (c) 2021 Tian, Liu, Cao, Zeng, Pan, Liu, Peng and Wu. This is an openaccess article distributed under the terms of the Creative Commons Attribution License (CC BY). The use, distribution or reproduction in other forums is permitted, provided the original author(s) and the copyright owner(s) are credited and that the original publication in this journal is cited, in accordance with accepted academic practice. No use, distribution or reproduction is permitted which does not comply with these terms. 